\title{
Endoscopic and gastric acid studies in homozygous sickle cell disease and upper abdominal pain
}

\author{
M G LEE, C H R THIRUMALAI, S I TERRY, AND G R SERJEANT \\ From the Departments of Medicine, Physiology and the Medical Research Council Laboratories, University of \\ the West Indies, Kingston, Jamaica
}

SUMmary Upper endoscopic and gastric acid output studies were done in 51 patients with homozygous sickle cell (SS) disease and recurrent epigastric pain. Twenty (39\%) had abnormalities in the upper gastrointestinal tract including $18(35 \%)$ with peptic ulcers. Mean basal and maximum acid output were similar in patients with and without duodenal ulcer (DU). Because DU in SS disease does not appear to be associated with high acid outputs observed in other populations, it may reflect reduced mucosal resistance, possibly resulting from ischaemia. This hypothesis was supported by the significantly lower fetal haemoglobin level among SS-DU patients.

Upper abdominal pain, occurring after meals and relieved by food and antacids, is common in patients with sickle cell disease (SS).' The cause of the pain remains unknown in most of these patients. Peptic ulceration has been considered rare in SS disease ${ }^{2}$ although one study reported 27 cases. $^{3}$

Gastric acid studies in SS disease have shown stimulated secretion to be normal ${ }^{t 5}$ and to remain in the normal range even in patients with SS disease and duodenal ulceration. ${ }^{3}$

The present study reports the clinical and endoscopic findings in the upper gastrointestinal tract and gastric acid secretion in patients with SS disease with recurrent upper abdominal pain suggestive of peptic ulcer disease.

\section{Methods}

\section{PATIENTS}

Patients age 16 years and over with SS disease, seen at the Sickle Cell Clinic of the University Hospital, Kingston, Jamaica, in the period April 1984-April 1987 were studied. The diagnosis of sickle cell disease was based on standard criteria. ${ }^{\circ}$ Haematological methods have been described elsewhere.?

Address for correspondence: Dr M G Lee, Department of Medicine, University of the West Indies, Kingston 7, Jamaica, West Indies.

Accepted for publication 20 October, 1988.
All patients with upper abdominal pain, suggestive of peptic ulcer disease were referred for further evaluation. A complete clinical history, physical examination, and routine blood investigation were done on each patient. Patients with active hepatic or biliary disease and those with acute sickle cell crisis were excluded from the study.

To evaluate the upper gastrointestinal tract an upper gastrointestinal endoscopy was carried out with a forward viewing panendoscope (Olympus GIF-XQ) while symptoms were present in the 51 patients with SS disease.

Gastric acid studies were done after an overnight fast, by passing a nasogastric tube (French gauge 14) to the dependent portion of the stomach and confirming its position by fluoroscopy. The stomach was emptied and four 15 minute collections of gastric juice made in order to obtain the basal secretion. Chlorpheniramine maleate, $10 \mathrm{mg}$ (Allen and Hanburys Ltd) was then administered intramuscularly. Thirty minutes later histamine acid phosphate (Eli Lilly) was slowly infused intravenously $(0.04 \mathrm{mg} /$ $\mathrm{kg}$ body weight/hour) for two hours. Gastric juice was collected in 15 minute aliquots for the entire two hour period. Maximum acid output was calculated from the last hour of histamine infusion and expressed as mmol per hour.

These studies were undertaken in 12 of 14 patients with SS disease and duodenal ulcer (SS-DU), in 16 of 
31 patients with SS disease without demonstrable abnormality of the upper gastrointestinal tract (SSnon-DU) and in 15 haematologically normal patients with chronic recurrent duodenal ulceration.

The protocol was reviewed and approved by the Ethical committee of the University Hospital, University of the West Indies, Jamaica. Informed written consent was obtained from all patients before the study.

The acid output data were analysed by one way analysis of variance and by the Kruskal-Wallis non parametric test. ${ }^{8}$ The distribution of haematological indices was compared by the Student's $t$ test. A $P$ value of less than 0.05 was assumed to be statistically significant.

\section{Results}

The study included 51 patients with SS disease (22 men, 29 women) with a mean age of 34.0 years (range 16-69). All had a history of recurrent epigastric pain with a mean duration of 3.8 years (range four weeks to 23 years). The pain was described as burning, sticking or gnawing, sometimes radiated to the midback and was relieved by milk and antacids. The pain was episodic, not associated with features of an abdominal painful crisis, and was clinically assessed as peptic ulcer disease. Epigastric tenderness was present in $21(41 \%)$, seven of whom had peptic ulcer.

Upper gastrointestinal endoscopy was abnormal in 20 patients, 14 with duodenal ulcer (DU), four with gastric ulcer, and two with macroscopic gastritis. In the DU group there were eight men and six women, with a mean age of 37 years and a mean duration of pain of five years. In the GU group there were three men and one woman, with a mean age of 40 years and a mean duration of pain of three years. In the remaining 31 patients (11 men, 22 women) no abnormality was found in the upper gastrointestinal tract. In the haematologically normal patients with recurrent DU, there were 11 men and four women with a mean age of 40 years (range 17-57) and a mean duration of pain of eight years (range four months to 22 years). The clinical features in the SS patients did not differ between the patients with peptic ulcers or those with endoscopically normal upper gastrointestinal tract. Four of the SS-DU, one of four SS-GU and one of the two patients with gastritis were tobacco smokers (three to 20 cigarettes/day) compared with five of the 31 SS-non-DU patients and seven of the 15 AA-DU patients who smoked.

\section{GASTRIC ACID STUDIES}

The mean basal acid outputs for the three groups were; SS-DU 1.23 (range 0-6.19), SS-non-DU 2.09 (range 0-8.88) and AA-DU 3.93 (range 0-9.07)

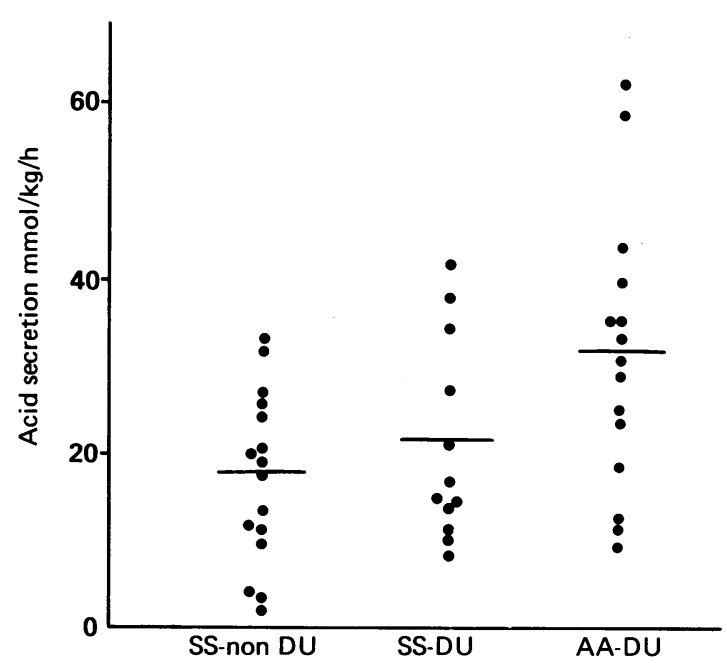

Fig. 1 Maximum gastric acid secretory rate in the three groups of patients.

$\mathrm{mmol} / \mathrm{h}$. Basal acid secretion in the AA-DU was significantly higher compared with the SS-DU $(p<0.01)$. The maximum acid outputs for the three groups are compared in Figure 1. There was no statistically significant difference between the maximum acid outputs (MAO) of the two groups of sicklers, however, the MAO of the AA-DU group was significantly higher than, that of the SS-DU group $(p<0 \cdot 05)$. Because sicklers as a group tend to have a smaller body frame than haematologically normal individuals, the MAO data were corrected for body weight and is displayed in Figure 2. The difference between the means for the two groups of

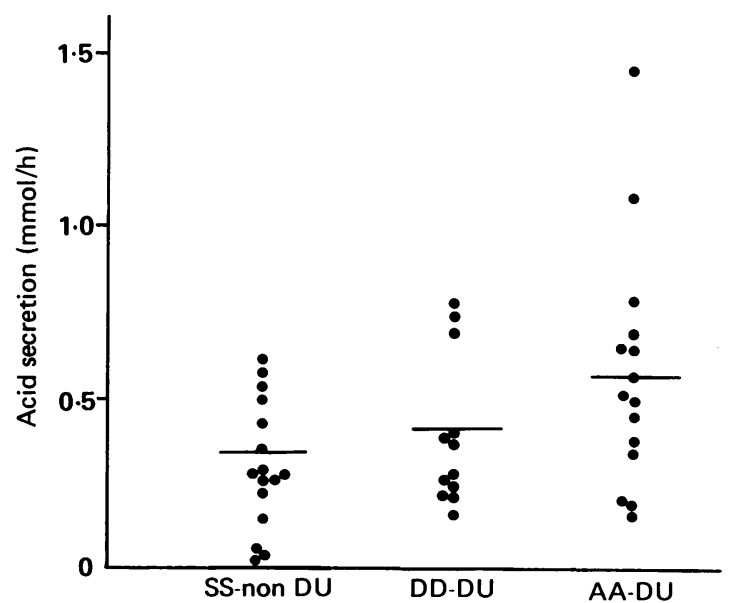

Fig. 2 Weight corrected maximum gastric acid secretory rate in the three groups of patients. 
Table Comparison of four haematological indices in 14 SS patients with and 31 without $D U$

\begin{tabular}{lrrrl}
\hline & SS-DU & SS-non-DU & \multicolumn{1}{l}{$t$} & \multicolumn{1}{l}{$p$} \\
\hline Haemoglobin (g/dl) & $7.44(0.86)$ & $8.02(0.90)$ & 2.04 & $<0.05$ \\
HbF $(\%)$ & $3.59(1.83)$ & $5.69(3.29)$ & 2.23 & $<0.05$ \\
Reticulocytes (\%) & $12.36(3.30)$ & $10.50(3.32)$ & 1.75 & $<0.1$ \\
ISC count (\%) & $10.40(5.64)$ & $8.48(4.49)$ & 1.04 & $<0.4$ \\
\hline
\end{tabular}

Mean (SD).

patients with sickle cell disease remained statistically insignificant, however, the MAO for the AA-DU group remained significantly higher than, that found in the SS-DU patients $(\mathrm{p}<0.05)$.

\section{RESPONSE TO THERAPY}

Of the 14 patients in the SS-DU group, six of seven were successfully treated with ranitidine $(150 \mathrm{mg}$ bd) and a further six of seven with antacids (mixture of aluminium and magnesium salts, seven times daily). Endoscopically confirmed healing occurred within four weeks. In one patient, ranitidine did not heal the ulcer after four weeks but the patient was symptomatically improved. One patient treated with antacids subsequently had surgery for his ulcer. Of the four patients with gastric ulcer, three were completely healed with ranitidine, and one with antacids. The majority of patients who had no abnormality in the upper gastrointestinal tract had symptomatic improvement with antacid therapy.

HAEMATOLOGICAL INDICES

Four steady state haematological indices in the SS-DU and SS-non-DU patients are compared in the Table. Total and fetal haemoglobin (HbF) levels were significantly lower in the SS-DU group $(p<0.05)$. There was no correlation, however, between total haemoglobin levels and maximal acid output.

\section{Discussion}

In this study, approximately one third of patients with SS disease with chronic recurrent epigastric pain had endoscopic evidence of peptic ulcer; with a predominance of duodenal $(27 \%)$ over gastric $(8 \%)$ ulcers. A prevalence of ulcer disease in SS disease cannot be extrapolated from this population, selected from a sickle cell clinic of more than 1000 patients, but is at least $3 \%$. There are no Jamaican or Caribbean data on the prevalence of peptic ulcer disease. In addition no data are available on the incidence of peptic ulcer disease in patients with SS disease. A prospective case control study would be required to answer definitely whether peptic ulcer disease is increased in SS disease.

The normal gastric acid output (basal and maximal) in our patients with SS-DU disease even when allowance is made for the smaller body weight of these patients suggests an association between ulcer disease and SS disease. This is in contrast with other patient populations with duodenal ulcers in which there is a constant $33 \%$ of DU patients whose acid output is increased beyond the normal range. ${ }^{4}$ In addition, basal and maximal acid output were similar in patients with SS disease with and without DU. Among haematologically normal subjects, however, duodenal ulceration is generally associated with higher basal and maximal acid output than in subjects without DU. ${ }^{1012}$ There are no data on gastric acid output in the normal Jamaican population. In this study the patients with SS disease and the haematologically normal patients were all black Jamaicans. Therefore ethnic variations in gastric acid output would not account for the difference between the groups.

These results suggest that factors other than maximal acid secreting capacity may be contributing to peptic ulcers in SS disease. Patients with SS disease are more prone to avascular damage at many sites in the body. That ischaemia plays a part in the susceptibility of SS disease patients to peptic ulcers is indicated by the significantly higher steady state total and fetal haemoglobin levels in SS patients without ulcers. Clinical severity of SS disease involves metabolic dysfunction in addition to areas of local ischaemia and the formation of an ulcer may be an indirect rather than a direct result of the severity of the sickle cell state.

Although gastric acid secretion was normal, peptic ulcer disease was present in one third of patients with sickle cell disease with recurrent epigastric pain. Reduced mucosal resistance associated with minor ischaemic events may be a contributory factor. Further studies on the pathogenesis of peptic ulcer in sickle cell disease are needed and may provide further insight into ulcer disease in general.

We wish to thank Miss Dawn Shand for assistance with the gastric acid analysis. We are grateful to the Wellcome Trust, The National Commercial Bank (Ja) Ltd, Blue Cross of Jamaica and the Jamaica Banana Producers Association for donations towards the purchase of equipment used in this study.

\section{References}

1 Serjeant GR, Richards R. Barbor PRH, Miller PR. Relatively benign sickle cell anaemia in 60 patients aged 
over 30 in the West Indies. Br Med J 1968; iii: 86-91.

2 Margolies MP. Sickle cell anaemia. A composite study and survey. Medicine 1951: 30: 357-443.

3 Serjeant GR, May H, Patrick A, Slifer ED. Duodenal ulceration in sickle cell anaemia. Trans $R$ Soc Trop Med Hyg 1973; 67: 59-63.

4 Zarafonetis CJD, Joseph RR, McMaster JD, Kolas JP. Osmolarity of gastric secretions in sicklemic individuals. $J$ Lab Clin Med 1961: 57: 600-3.

5 Wosornu L, Konotey-Ahulu FID. Gastric acid secretion in sickle cell anacmia. Gut 1971; 12: 197-9.

6 Serjeant GR. Sickle cell disease. Oxford: Oxford University Press, 1985.

7 Serjeant GR, Grandison Y, Lowric Y, et al. The development of haematological changes in homozygous sickle cell disease: a cohort study from birth to six years. Br J Haematol 1981; 48: 533-43.

8 Kruskal WH, Wallis WA. Use of ranks on one criterion variance analysis. J Am Stat Assoc 1952; 47: 583-621.

9 Lam SK. Hasan M. Sircus W, Wong J, Ong GB, Prescott RJ. Comparison of maximal acid output and gastrin response to meals in Chinese and Scottish normal and duodenal ulcer subjects. Gut 1980; 21: 324-8.

10 Vesely KT, Kubickova Z, Dvorakova M, Zvolankova $K$. Clinical data and characteristics differentiating types of peptic ulcer. Gut 1968; 9: 57-68.

11 Menguy R. Pathophysiology of peptic ulcer. Am J Surg 1970; 120: $282-8$.

12 Tovey F. Peptic ulcer in India and Bangladesh. Gut 1979; 20: 329-47. 